\title{
Enhanced absorption and tissue distribution of paclitaxel following oral administration of DHP 107, a novel mucoadhesive lipid dosage form
}

\author{
Beom Soo Shin · Hyoung Jun Kim • Seok Hyun Hong • \\ Jong Bong Lee $\cdot$ Sang Wook Hwang $\cdot$ \\ Mann Hyung Lee $\cdot$ Sun Dong Yoo
}

Published online: 28 February 2009

(C) Springer-Verlag 2009

\section{Erratum to: Cancer Chemother Pharmacol} DOI 10.1007/s00280-008-0849-9

In this Fig. 2, there are 8 small sub-figures for 8 different tissues. Of these, one sub-figure (Stomach, left panel, top) has been revised (open and filled symbols switched for the stomach only), and the rest 7 tissues are and unchanged. The figure legend is also unchanged.

The online version of the original article can be found under doi:10.1007/s00280-008-0849-9.

\section{B. S. Shin · M. H. Lee}

College of Pharmacy, Catholic University of Daegu,

Gyeongsan-si, Gyeongbuk, South Korea

H. J. Kim · S. H. Hong · J. B. Lee · S. W. Hwang · S. D. Yoo (凹)

College of Pharmacy, Sungkyunkwan University,

300 Cheoncheon-dong, Jangan-gu, Suwon,

Gyeonggi-do 440-746, South Korea

e-mail: sdyoo@skku.ac.kr 
Fig. 2 Average tissue concentration-time profiles of paclitaxel after i.v. injection of 5 (open circle), 10 (open square) and 20 (open triangle) $\mathrm{mg} / \mathrm{kg}$ doses of Taxol and oral administration of 10 (filled circle), 20 (filled square) and 40 (filled triangle) $\mathrm{mg} / \mathrm{kg}$ doses of DHP 107 in mice ( $n=4$ per sampling time)
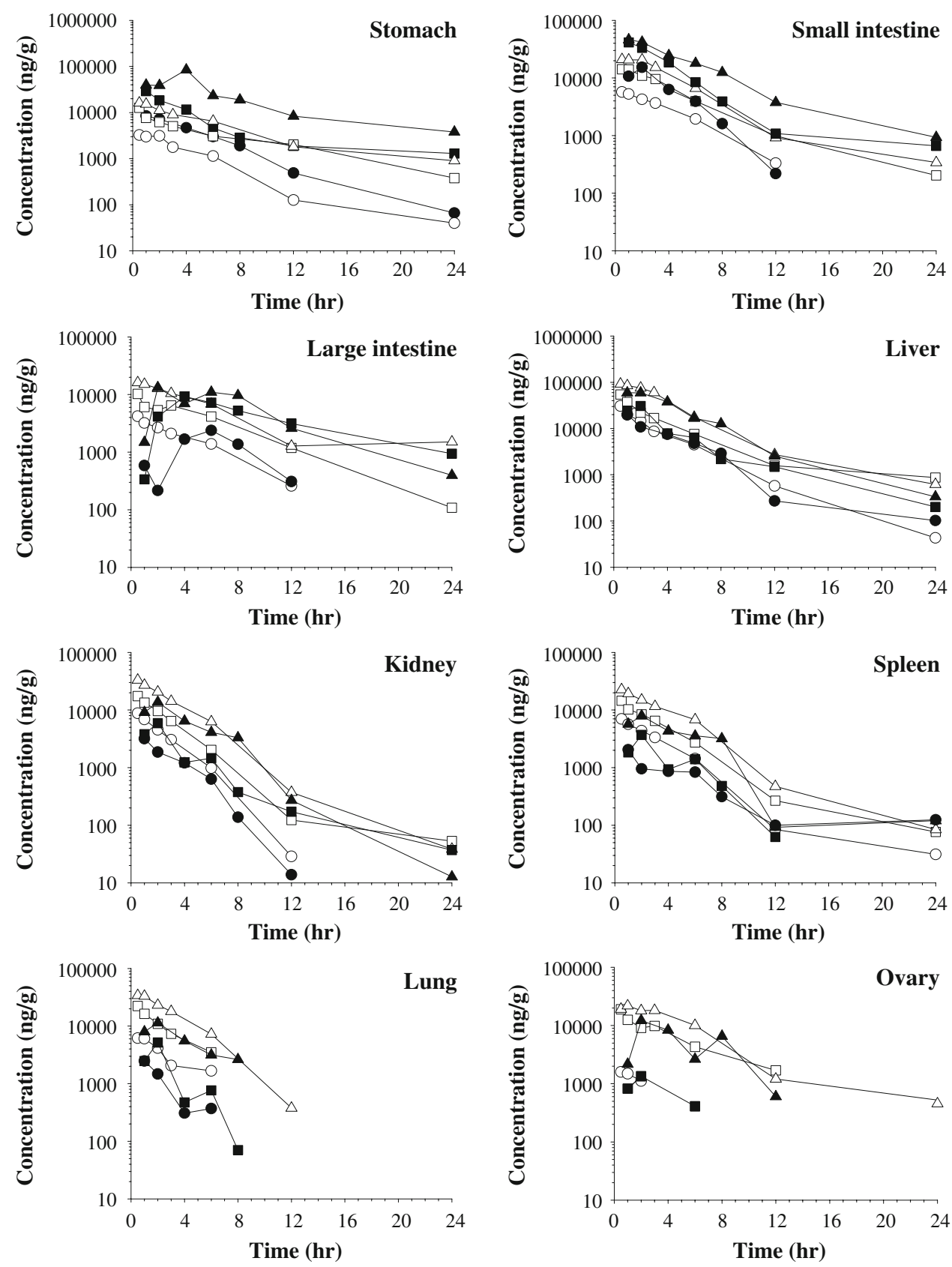